Elsevier Editorial System(tm) for Fertility and Sterility

Manuscript Draft

Manuscript Number: F and S5688R2

Title: Up-regulation of Endocrine Gland-derived Vascular Endothelial Growth Factor (EGVEGF/PK1) but not VEGF in Human Ectopic Endometriotic Tissue

Article Type: Reproductive Biology

Section/Category:

Keywords: Endometriosis; Endometrium; Laser capture micro-dissection; EG-VEGF; PK1; PKR1;

PKR2

Corresponding Author: Dr Kai-Fai Lee, Ph D

Corresponding Author's Institution: The University of Hong Kong

First Author: Kai-Fai Lee, Ph D

Order of Authors: Kai-Fai Lee, Ph D; Yin-Lau Lee, Ph D; Rachel W Chan, Ph D; Ana W Cheong, M Sc; Ernest H Ng, MD; Pak-Chung Ho, MD; William S Yeung, Ph D

Abstract: Objective: To study the expression of vascular endothelial growth factor (VEGF), endocrine gland-derived VEGF (EG-VEGF/PK1) and its receptors (PKR1 and PKR2) in eutopic and ectopic endometrial tissues. Design: A case control study. Setting: University reproduction unit. Patients: Infertile women undergoing diagnostic laparoscopy for tubal patency. Intervention: Endometrial and endometriotic tissue sampling from women with and without endometriosis. Main Outcome Measure(s): Quantitative PCR analysis of genes in eutopic and ectopic endometrial tissues. EG-VEGF protein was studied by immunohistochemistry. Result(s): In normal endometrium, EG-VEGF mRNA expression was 50-fold higher $(p<0.05)$ in the secretory than in the proliferative phase, but that of PKR1 was 6-fold higher in the latter than in the former. PKR2 transcript was detected in the proliferative but not the secretory endometrium. In patients with 
endometriosis, eutopic endometrial PKR2 transcript level was 4-fold higher $(p<0.05)$ in the proliferative than in the secretory phase. No differences in EG-VEGF nor PKR1 in proliferative versus secretory endometrium in these patients were found. There were no significant differences in the expression of EG-VEGF in eutopic endometrium of normal women and those with endometriosis. In the paired laser captured micro-dissected eutopic endometrial and ectopic endometriotic samples, a significantly higher $(p<0.01)$ EG-VEGF but not VEGF transcript level was detected in the ectopic when compared to eutopic samples; while the expressions of PKR1 and PKR2 were barely detectable.....

Suggested Reviewers:

Opposed Reviewers: 
Running Title: EG-VEGF/PK1 in Human Endometriotic Tissues

1

2

3

4

5

6

7

8

10

11

12

13

14

15

16

17

18

19

20

21

22

23

24

25

26

27

28

29

30

31

32

33

34

35

36

37

38

39

40

41

42

43

44

45

46

47

48

49

50

51

52

53

54

55

56

57

58

59

60

61

62

63

64

65 


\section{Up-regulation of Endocrine Gland-derived Vascular Endothelial Growth Factor (EG-VEGF/PK1) but not VEGF in Human Ectopic Endometriotic Tissue}

Kai-Fai Lee, Ph.D., ${ }^{\text {a,b,c,* }}$, Yin-Lau Lee, Ph.D., ${ }^{\text {a,c }}$, Rachel W.S. Chan, Ph.D., ${ }^{a}$ Ana W.Y. Cheong, M.Sc., ${ }^{a}$ Ernest H.Y. Ng, M.D., a,b Pak-Chung Ho, M.D.,, ${ }^{1,2}$ William S.B. Yeung, Ph.D., ${ }^{\mathrm{a}, \mathrm{b}, *}$

${ }^{\mathrm{a}}$ Department of Obstetrics and Gynaecology, and ${ }^{\mathrm{b}}$ Center of Reproduction, Development and Growth, LKS Faculty of Medicine, The University of Hong Kong, Pokfulam, Hong Kong, China

${ }^{\mathrm{c}}$ The first two authors contributed equally to the work.

Supported in part by grants from the General Research Fund (GRF), Research Grant Council (HKU 7395/04M and HKU 7514/05M) to PCH and CRCG grants to KFL.

* Reprint requests: Kai-Fai Lee Department of Obstetrics and Gynecology, The University of Hong Kong, Pokfulam, Hong Kong (Fax: 852-2816-1947; E-mail: ckflee@hkucc.hku.hk) or William S.B. Yeung, (Fax: 852-2855-0947; Email: wsbyeung(hkucc.hku.hk) 
Capsule: High levels of EG-VEGF expression may play an important role in

1

2

3

4

5

6

7

8

9

10

11

12

13

14

15

16

17

18

19

20

21

22

23

24

25

26

27

28

29

30

31

32

33

34

35

36

37

38

39

40

41

42

43

44

45

46

47

48

49

50

51

52

53

54

55

56

57

58

59

60

61

62

63

angiogenesis in endometriotic tissues. 


\section{Abstract}

Objective: To study the expression of vascular endothelial growth factor (VEGF), endocrine gland-derived VEGF (EG-VEGF/PK1) and its receptors (PKR1 and PKR2) in eutopic and ectopic endometrial tissues. Design: A case control study. Setting: University reproduction unit. Patients: Infertile women undergoing diagnostic laparoscopy for tubal patency. Intervention: Endometrial and endometriotic tissue sampling from women with and without endometriosis. Main Outcome Measure(s): Quantitative PCR analysis of genes in eutopic and ectopic endometrial tissues. EG-VEGF protein was studied by immunohistochemistry. Result(s): In normal endometrium, EG-VEGF mRNA expression was 50-fold higher $(p<0.05)$ in the secretory than in the proliferative phase, but that of PKR1 was 6-fold higher in the latter than in the former. PKR2 transcript was detected in the proliferative but not the secretory endometrium. In patients with endometriosis, eutopic endometrial PKR2 transcript level was 4 -fold higher $(p<0.05)$ in the proliferative than in the secretory phase. No differences in EG-VEGF nor PKR1 in proliferative versus secretory endometrium in these patients were found. There were no significant differences in the expression of EG-VEGF in eutopic endometrium of normal women and those with endometriosis. In the paired laser captured micro-dissected eutopic endometrial and ectopic endometriotic samples, a significantly higher $(\mathrm{p}<0.01)$ EG-VEGF but not VEGF transcript level was detected in the ectopic when compared to eutopic samples; while the expressions of PKR1 and PKR2 were barely detectable. H-scoring confirmed that the stroma of endometriotic samples had a significantly higher $(p<0.05)$ EG-VEGF protein expression than that in the paired eutopic endometrium. Conclusion(s): High levels of EG-VEGF expression may play an important role in angiogenesis in endometriotic tissues. 
Key Words: Endometriosis, Endometrium, Laser capture micro-dissection, EG-VEGF, PK1, PKR1, PKR2 


\section{INTRODUCTION}

Endometriosis refers to the presence of endometrial tissues outside the uterine cavity. It occurs spontaneously in humans and non-human primates including baboons and macaques but is rare in other animal species (1). Endometriosis is a common gynaecological disease affecting 6-10\% women of reproductive age. Affected women have higher risk than the general female population in developing cancers, autoimmune and atopic disorders (2). Its etiology and pathophysiology are still unclear. Endometrial tissues in the uterus (eutopic) and outside the uterine cavity (ectopic) respond to the cyclical changes of steroid hormones. However, the proportions of estrogen and progesterone receptors, as well as the histology are different between paired eutopic and ectopic endometrial samples (3-5).

Angiogenesis is important in the development of endometriosis (6-8). Angiostatic treatment reduces the number of endometriotic lesions at implantation in the chick chorioallantoic membrane model (9) and after implantation in the nude mice model (10). Various growth factors including vascular endothelial growth factor (VEGF) have been found to be associated with angiogenesis in endometriosis $(6,10$, 11).

Endocrine gland-derived vascular endothelial growth factor (EG-VEGF) belongs to the prokineticin family. It is also known as prokineticin 1 (PK1), and shares about 44\% amino acid homology with prokineticin 2 (PK2) or Bv8 (12). EG-VEGF was previously thought to be selectively expressed in steroidogenic glands and stimulate the growth of endocrine gland endothelium (13). It promotes proliferation, survival, and chemotaxis of endothelial cells from steriodogenic tissue, such as adrenal cortex capillary endothelial cells (14), but not those from other tissues, such as human umbilical vein endothelial cells and other non-endothelial cell types 
$(12,13)$. Although EG-VEGF is structurally distinct from VEGF, they induce similar angiogenic response in the ovary $(15,16)$.

EG-VEGF acts via G-protein coupled receptors, PKR1 and PKR2 (17, 18), and induces mitogen-activated protein kinase (MAPK) and Akt serine/threonine kinase phosphorylation in bovine adrenal capillary endothelial cells (17), HEK293 (18), adrenal cortex-derived endothelial (ACE) cells (19), neuroblastoma cell line (SK-N-SH, 20) and human uterine microvascular endothelial cell (Ut-HVEC-Myo, 21). Human PKR1 and PKR2 shared $85 \%$ amino acid identity and are most divergent in their N-terminal sequences (18).

Prokineticins and their receptors are likely to be involved in reproduction as they are expressed in male reproductive tissues including testis and prostate $(22,23)$, and in female reproductive tissues such as ovary, uterus and various tissues during pregnancy $(16,24,25)$. EG-VEGF has also been implicated in the pathology of the reproductive tract (26), including Leydig cell neoplasms (27), prostate cancer (23), ovarian carcinoma (15) and polycystic ovarian syndrome (16). Whether EG-VEGF is involved in endometriosis is unclear. During early pregnancy and in hypoxic conditions, hypoxia-inducible factor-1 $\alpha(\mathrm{HIF}-1 \alpha)$ binds to the promoter of EG-VEGF and PKR1 leading to up-regulation of these genes in the placenta $(13,25,26)$.

Interestingly, transient hypoxia also up-regulates HIF-1 $\alpha$ and induces the expression of VEGF in endometrium (28) and transplanted endometriosis-like lesions (29). In the mice model, suppression of HIF-1 $\alpha$ decreases VEGF production and inhibits growth of the transplanted endometriosis-like lesions (29).

Recently, EG-VEGF was found to be expressed in non-endocrine tissues including endometrium $(26,30,31)$. In human endometrium, EG-VEGF is highly expressed in the secretory phase of the menstrual cycle when active angiogenesis occurs $(30,31)$. The facts that EG-VEGF is detected only in steroid (estradiol and progesterone) treated endometrial epithelial and stromal cells, and is up-regulated in 
the peri-implantation endometrium after gonadotropin-stimulation and hormone replacement therapy suggests that the production of EG-VEGF is hormone dependent $(30,31)$. Despite all these observations, the function of EG-VEGF in the uterus remains unknown.

In view of the importance of angiogenesis in the development and progression of endometriosis, the involvement of multiple factors in the regulation of angiogenesis and HIF-1 $\alpha$ target genes in endometriosis, and the potential angiogenic role of EG-VEGF in endometrium, we hypothesized that aberrant expression of EG-VEGF could be associated with the pathogenesis of endometriosis. In this study, we used laser micro-dissection technique to isolate paired human eutopic and ectopic endometriotic biopsies for real-time PCR analysis on VEGF, EG-VEGF and PKR1 and PKR2 mRNA expression. The increased expression of EG-VEGF mRNA and protein in ectopic endometriotic tissues suggests this molecule is associated with the progression of the disease. 


\section{MATERIALS AND METHODS}

\section{Human Subjects}

Infertile women with endometriosis shown on diagnostic laparoscopy for assessment of tubal patency were recruited. The eutopic endometrial (DE) samples from these diseased women $(n=15)$ were obtained by pipelle. The American Society for Reproductive Medicine (ASRM) rAFS scoring was used to classify the stages of the disease. Eutopic endometrial samples were also taken from 33 normal women (NE) who had no endometriosis as determined by laparoscopic examination and had regular menstrual cycles. There were no difference between the mean age (normal: 33, range 24-39; endometriosis: 34, range 29-38, $>>0.05$ ) and mean cycle length (normal: 30 , range 26-35 days; endometriosis: 30 , range $25-35$ days, $p>0.05$ ) of the normal and the diseased groups. For the paired eutopic and ectopic endometriotic samples $(n=16)$, tissues at proliferative phase $(n=4)$ and secretory phase $(n=12)$ were obtained from women with endometriosis (age: 31-49). All recruited subjects had not received any anti-inflammatory or hormonal medication for at least three months prior to the sample collection. The classification of the endometrial samples into proliferative or secretory phases was based on the day of the last menstrual period and was confirmed by endometrial histology (32). The Institutional Review Board of the University of Hong Kong/Hospital Authority Hong Kong West Cluster had approved the protocol of the study and informed consent was received from each subject.

\section{Laser Captured Micro-dissection (LCM) and Real-time PCR}

The endometrial and endometriotic tissues were snap-frozen, embedded in OCT medium and cut into $6 \mu \mathrm{m}$ thick sections at $-20^{\circ} \mathrm{C}$. Ectopic endometrial samples containing glandular and stromal cells were isolated by laser captured micro-dissection (LCM) to avoid contamination by ovarian stromal tissue. Eutopic 
F \& S 5688 revision

endometrial samples were processed similarly as sham procedure before RNA extraction. In brief, frozen tissue sections were mounted on a membrane slide with a 2 $\mu \mathrm{m}$ thick membrane framed by aluminum and stained with hematoxylin and eosin for histological examination. After drying in air for $10 \mathrm{~min}$, the membrane slide was placed on a regular glass slide, which was put on the microscopic stage with the membrane slide facing up (Leica DM IRB, Leica Microsystems Ltd.). Glandular and stomal tissues were micro-dissected using a laser beam (VSL-337ND-S nitrogen laser, Laser Science Inc.) and picked up by the capturing caps. The attached tissues were then put directly into microcentrifuge tubes. RNA from three captured tissues were extracted with the Absolute RNA Miniprep Kit (Stratagene, CA, USA) as described previously (33) and eluted with $30 \mu \mathrm{l}$ of distilled water. One-third of the total RNAs from each sample were reverse-transcribed into cDNA using the First-strand cDNA Synthesis Kit (Amersham Pharmacia, Buckinghamshire, UK). Real-time PCR analysis of human VEGF, EG-VEGF, PKR1 and PKR2 transcripts were performed using an ABI 7500 Sequence Detector (PE Applied Biosystems, Foster City, CA). Multiplex PCR reactions were carried out in a $20 \mu \mathrm{l}$ reaction mixture containing $2 \mu \mathrm{l}$ of sample cDNA; $10 \mu \mathrm{l} 2 \mathrm{X}$ TaqMan Universal PCR Master Mix; $1 \mu 1$ of $18 \mathrm{~S}$ internal control and $1 \mu \mathrm{l}$ of 20X Assays-on-Demand Gene Expression Assays (PE Applied Biosystems) in triplicates. The qPCR experiment was repeated thrice for the 16 pairs of RNA samples. Quantitative analysis was done by the sequence detection software supplied with the ABI 7500 Sequence Detector. The threshold cycles $(\mathrm{Ct})$ for each reaction were calculated and used for quantifying the amount of starting template in the reaction. A difference of $\mathrm{Ct}$ values $(\Delta \mathrm{Ct})$ was obtained by subtracting the $\mathrm{Ct}$ value of $18 \mathrm{~S}$ from $\mathrm{Ct}$ value of the genes of interest. The relative gene expression values were calculated by the $2^{-\Delta \Delta C t}$ method (34). The relative amount of the transcript of interest in the normal sample (X) and the diseased sample (Y) after normalization to 
an endogenous reference (18S) was calculated as $2^{-\Delta \Delta \mathrm{Ct}}$, where $\Delta \mathrm{Ct}$ is the difference

in $\mathrm{Ct}$ between the gene of interest and 18S, and $\Delta \Delta \mathrm{Ct}$ is the difference for sample $\mathrm{X}$ and $\mathrm{Y}$ i.e. $\Delta \mathrm{Ct}_{\mathrm{X}}-\Delta \mathrm{Ct}_{\mathrm{Y}}$. The expression levels in normal endometrium or in proliferative phases were used as calibrators for different PCR experiments.

\section{Immunohistochemical Staining}

Antibody against human EG-VEGF was obtained from R\&D Systems (MAB1209, Minneapolis, MN). Frozen endometrial and testicular sections were acetone and then methanol fixed for $5 \mathrm{~min}$ and the tissues were blocked by $10 \%$ rabbit serum in PBS for 30 minutes. A 1:100 dilution of the antibody was used and the tissues sections were incubated at $4^{\circ} \mathrm{C}$ overnight. The tissues were washed 5 times with PBS, incubated with 1:300 diluted rabbit anti-mouse biotinylated secondary antibody for 60 minutes, and were incubated with the $\mathrm{ABC}$ complex (Vectastain $\mathrm{ABC}$ kit, Vector, Burlingame, CA) for $30 \mathrm{~min}$. Specific signal were visualized by DAB staining and the tissues were counterstained with hematoxylin. Semi-quantitative assessment of staining $(\mathrm{n}=12)$ was done on 5 fields of epithelial and stromal tissues by $\mathrm{H}$-score (35), which was calculated as: $\mathrm{H}$ score $=\Sigma \mathrm{Pi}(\mathrm{i}+1)$, where $\mathrm{i}=$ staining intensity graded as $0,1,2$ and 3 with 3 being the highest intensity, and $\mathrm{Pi}=$ percentage of tissue staining at each intensity.

\section{Statistical Analysis}

Data were analyzed using the SigmaPlot software package (Jandel Scientific, San Rafael, CA). Statistical analysis was performed by Kruskal-Wallis and Mann-Whitney $U$ test or paired $t$-test as appropriate. Linear associations of American Society for Reproductive Medicine's classification rAFS scores on the endometriosis 
patients with EG-VEGF, PKR1 and PKR2 mRNA expression were tested using Pearson's correlation coefficient. A p-value $<0.05$ was considered statistically significant. 


\section{RESULTS}

\section{Expression of EG-VEGF, PKR1 and PKR2 in Normal and Eutopic \\ Endometrial Tissues}

To determine if there were differences in the mRNA expression levels of EG-VEGF, PKR1 and PKR2 between eutopic endometrium from normal women (NE, $\mathrm{n}=33$ ) and eutopic endometrium of diseased women with endometriosis (DE, $n=15)$, tissue samples were divided into 4 groups: normal proliferative endometrium $(n=14)$, normal secretory endometrium $(\mathrm{n}=19)$; eutopic proliferative endometrium with endometriosis $(n=9)$ and eutopic secretory endometrium with endometriosis $(n=6)$. The relative expression of the three transcripts was normalized to $18 \mathrm{~S}$ and calculated by the equation: $2^{-\Delta \Delta \mathrm{Ct}}$ using the proliferative phase normal endometrium $(\mathrm{NE})$ as calibrator. It was found that normal endometrium (NE) at secretory phase expressed significantly $(\mathrm{p}<0.05)$ higher EG-VEGF $(50$-fold) but lower PKR1 (6-fold) mRNA when compared with that of the normal proliferative phase samples (Table 1, Figure 1A and B). PKR2 transcript was detected in the normal proliferative endometrium but not in the normal secretory endometrium. (Table 1 and Figure 1C). The expression of PKR2 in the eutopic proliferative endometrium from patients with endometriosis (DE; Table 1 and Figure 1C) was significantly higher $(4-$ fold, $p<0.05)$ than that in the eutopic secretory endometrium. However, no difference was found in EG-VEGF and PKR1 expression between the proliferative and secretory eutopic endometria from patients with endometriosis (Figure 1A and B). When the expression of the three genes in endometrial biopsies of the same menstrual phase was compared, no difference was found between the normal and the endometriosis groups. The rAFS scores of the endometriosis patients ranges from 1 to 85 with a median value of 4 . Analysis of the relationship between rAFS scores of the endometriosis patients and the mRNA expression of EG-VEGF, PKR1 and PKR2 had a coefficient of correlation 
(r) of $-0.136,0.0122$ and -0.0152 , respectively $(\mathrm{p}>0.05)$, indicating that the gene expressions were not correlated with the rAFS scores (data not shown).

\section{Expression of EG-VEGF, PKR1 and PKR2 in the Paired Eutopic and Ectopic Endometriotic Samples}

We further analyzed the expression of VEGF and EG-VEGF mRNA in another sixteen paired human endometriotic samples (Figure 2A) in which 4 were in proliferative and 12 were in secretory phases by real-time PCR. The LCM isolated tissues from eutopic and ectopic samples contained a mixture of glandular and stromal tissues. Multiplex real-time PCR were carried out and the data were normalized with $18 \mathrm{~S}$ and calculated by the equation: $2^{-\Delta \Delta \mathrm{Ct}}$ using the ectopic endometrium as calibrator.. No significant difference was found in VEGF expression (Figure 2B) between the eutopic and ectopic endometiotic samples (1.922 vs 1.151, $\mathrm{p}>0.05$ ), but a significant increase in EG-VEGF expression (Figure 2B) between the eutopic and ectopic endometriotic samples $(0.140$ vs $2.131, \mathrm{p}=0.00879)$ was observed. Subgroup analysis of the secretory phase samples demonstrated the expression of EG-VEGF in ectopic endometrium is significantly higher than that of the eutopic endometrium (0.202 vs $1.970, p=0.0159)$; while no significant change in VEGF expression was found. Very low or undetectable expression of PKR1 and PKR2 were observed, i.e. Ct value close to 40 cycles, in both the eutopic and ectopic endometriotic samples (data not shown).

\section{EG-VEGF Protein Expression in Ectopic Endometriotic Tissues}

Immunohistochemical staining was performed using EG-VEGF antibody on frozen paired endometrial tissues. EG-VEGF immunoreactivity was strongly localized to the glandular and luminal epithelium of the eutopic endometrial samples (Figure 
3A) and the expression of EG-VEGF in the stromal cells were weak. In ectopic endometriotic samples, intense EG-VEGF immunostaining was found in the stromal cells (Figure 3B). No immunostaining was found when the primary antibody was omitted (Figure 3C). The specificity of the antibody was confirmed when frozen human testicular section was used (Figure 3D) and specific signal was observed in the Leydig cells of the testis. The expression of EG-VEGF protein in twelve pairs of endometriotic samples was determined by H-scoring (Figure 3E and F). Significant difference was found in the stromal cells (Median and range: $1.5(0.5-2.4)$ vs 0.5 $(0-2.2), p=0.011)$, but not in the glandular epithelium (Median and range: $1.4(0.2-2.0)$ vs $1.5(1.0-2.4), \mathrm{p}>0.05)$ of ectopic and eutopic sample, respectively. 


\section{DISCUSSION}

The expression of EG-VEGF in human endometrium was up-regulated in the secretory phase of the menstrual cycle (Figure 1A), consistent with a steroid regulatory mechanism of EG-VEGF production. Higher expression of EG-VEGF was also found in the gonadotropin-stimulated cycle when compared with the natural cycle of patients undergoing assisted reproduction treatment (30). The hormonal regulation of EG-VEGF expression by progesterone has also been demonstrated using cultured endometrial tissues (31). Furthermore, our recent study demonstrated that estrogen and/or progesterone stimulate EG-VEGF expression in the human primary endometrial stromal and glandular epithelial cells (30).

We detected a higher PKR1 and PKR2 mRNA expression in eutopic endometrial samples from normal women (NE) in the proliferative phase (Figure 1B and C) than in the secretory phase suggesting that the receptors for EG-VEGF (PKR1 and PKR2) may be mainly regulated by estrogen. The differential expression pattern of PKR2, but not PKR1, was also found in the proliferative and secretory eutopic endometria from patients with endometriosis (DE). However, no significant temporal variation of PKR1 and PKR2 mRNA expression was found between the human proliferative and secretory endometria in another study (31). The reasons for this discrepancy remain unknown. It could be due to the inclusion of the full-thickness of the endometrium with basal endometrial-myometrial region expressing low level of PKR2 in the previous study, whereas only the superficial endometrial layer was analyzed in the present study.

It was interesting to note that the level of EG-VEGF was low whilst that of the transcripts of EG-VEGF receptors (PKR1 and PKR2) was up-regulated in the proliferative endometrium when compared to the secretory endometrium in normal samples. The reason for the dissonance in the expression between EG-VEGF and its 
receptors was not clear. It was possible that EG-VEGF/PK1 could act on another receptor yet to be defined in the secretory endometrium. In line with this, endometrium expresses another ligand of PKR1 and PKR2, PK2 with level that does not vary significantly in the menstrual cycle (31). PK2 has a long form spliced variant, PK2L, which is co-expressed with PK2 in many tissues (36). PK2L produces a peptide, PK2 $\beta$ that can selectively activate PKR1 (36). The abundance of PK2L in endometrium at different phases of the menstrual cycle is not known. Its determination would be useful to verify the existence of the second possibility.

PKR1 and PKR2 share $87 \%$ homology in amino acid sequences and have almost identical transmembrane domain sequence (37), suggesting that they may have similar activation mechanism (26). However, it was reported that EG-VEGF induces phosphorylation of p44/42 MAPK in the PKR1 transfected cells but not in the PKR2 transfected cells (18). In mouse, PKR2 is essential for the maturation of the reproductive system as its deficiency is associated with atrophy of the reproductive tract including gonads and endometrium, which has been linked to the lack of gonadotropin-releasing hormone neurons in the hypothalamus (38). Yet, no abnormality in the reproductive tract of PKR1 knockout mice was found $(38,39)$.

When endometrial tissues in the same menstrual phase were compared, there was no significant difference in the mRNA expression of EG-VEGF and its receptors between the normal endometrium and eutopic endometrium from women with endometriosis, indicating that eutopic EG-VEGF expression was not associated with the occurrence of endometriosis. This observation was supported by the present results showing no correlation between the severity of endometriosis (ASRM endometriosis scores) and the mRNA expression of EG-VEGF, PKR1 and PKR2 in the eutopic endometrium.

Human ovary abundantly expresses EG-VEGF and PKR2 but not PKR1 (14, 18). In order to avoid contamination of endometriotic tissues by neighboring ovarian 
tissue, we used laser captured micro-dissection to isolate endometriotic tissues. The purity of the laser micro-dissected samples was demonstrated by the very low or undetectable level of PKR2, which is known to be produced abundantly in the ovary. The micro-dissected ectopic endometriotic tissues used in this study contained both epithelial and stromal cells. They produced EG-VEGF but not its receptors, suggesting paracrine actions of the EG-VEGF most probably act on the neighboring ovarian cells which express PKR2. Consistent with this possibility is the observation that over-expression of EG-VEGF in the rat ovary resulted in excessive angiogenesis and cysts formation (13). Thus, the increase in EG-VEGF expression in ectopic endometrium when compared with that in the eutopic endometrium is likely to be an event secondary to the initiation of ovarian endometriosis. The expression of EG-VEGF is also associated with polycystic ovary syndrome (16). The aetiology of EG-VEGF over-expression in ovarian endometriotic cyst warrants further investigation.

Angiogenesis is important in the establishment and growth of endometriosis. In the ovary, the angiogenic response induced by EG-VEGF is indistinguishable from that by VEGF (14). However, the expression of ovarian EG-VEGF and VEGF is temporally and spatially complementary to each other (16), suggesting that the two growth factors have distinct roles and targets in ovarian functions. This may explain why up-regulated levels of EG-VEGF could induce pathophysiological changes in endometriosis even in the presence of other potent angiogenic factors like VEGF.

In the present study, a significant increase in EG-VEGF protein expression was found in the stromal cells of ectopic endometrium (Fig. 3B and E). It is possible that the stromal cells may synthesize more EG-VEGF and/or EG-VEGF is synthesized in the epithelial cells but is accumulated in the extracellular matrix of the stroma. The latter explanation was supported by the fact that VEGF binds to the extracellular matrix upon secretion (40) and releases during tissue breakdown or 
F \& S 5688 revision hypoxia. EG-VEGF is a heparin-binding molecule (13) and the heparin-binding

domain of VEGF interacts with the matrix proteins (41). Thus, EG-VEGF may also be accumulated in the extracellular matrix giving an intense immuno-positive signal. The current data cannot distinguish these two possibilities.

VEGF is generally accepted as a critical angiogenic factor associated with implantation and early pregnancy (42), though there are opposing opinions $(43,44)$. Although the expression of VEGF mRNA and protein was higher in red peritoneal endometriotic lesion than in other type of peritoneal lesions $(45,46)$, no difference in the mRNA expression of VEGF between eutopic endometrium and ovarian endometriotic tissues was found in the present study. This observation supports a recent report on lack of difference in VEGF immunorectivities between eutopic endometrium and ovarian endometriosis (47). There is also no difference in the mRNA and protein production of VEGF by granulose-luteal cells in women with or without ovarian endometriomas (48).

In conclusion, we have demonstrated an up-regulation of EG-VEGF but not VEGF in ectopic endometriotic tissues obtained from same patients. The absence and/or low expression of EG-VEGF receptors (PKR1 and PKR2) in the ectopic endometriotic tissues suggested that EG-VEGF may act as paracrine and endocrine factors to promote angiogenesis in adjacent tissues leading the paracrine disorder in women. Further studies on the functional role of EG-VEGF, PKR1, PKR2 and VEGF on the pathophysiological changes in ectopic endometrium in vitro and in animal model will provide a better understanding on the causes of endometriosis and may lead to possible medical treatments for the prevention of this disease. 


\section{Acknowledgments}

We thank patients who donated their endometrial samples. This study was supported by grants from the General Research Fund (GRF), Research Grant Council (HKU 7395/04M and HKU 7514/05M) to PCH and CRCG grants to KFL. 


\section{References}

1. D'Hooghe TM. Clinical relevance of the baboon as a model for the study of endometriosis. Fertil Steril 1997; 68:613-25.

2. Giudice LC, Kao LC. Endometriosis. Lancet 2004; 364:1789-99.

3. Lessey BA, Metzger DA, Haney AF, McCarty KS Jr. Immunohistochemical analysis of estrogen and progesterone receptors in endometriosis: comparison with normal endometrium during the menstrual cycle and the effect of medical therapy. Fertil Steril 1989; 51:409-15.

4. Prentice A, Randall BJ, Weddell A, McGill A, Henry L, Horne CH, et al. Ovarian steroid receptor expression in endometriosis and in two potential parent epithelia: endometrium and peritoneal mesothelium. Hum Reprod 1992; 7:1318-25.

5. Misao R, Iwagaki S, Fujimoto J, Sun W, Tamaya T. Dominant expression of progesterone receptor form B mRNA in ovarian endometriosis. Horm Res 1999; $52: 30-4$.

6. Hull ML, Charnock-Jones DS, Chan CL, Bruner-Tran KL, Osteen KG, Tom BD, et al. Antiangiogenic agents are effective inhibitors of endometriosis. J Clin Endocrinol Metab 2003; 88:2889-99.

7. Groothuis PG, Nap AW, Winterhager E, Grümmer R. Vascular development in endometriosis. Angiogenesis 2005; 8:147-56.

8. Girling JE, Rogers PA. Recent advances in endometrial angiogenesis research. Angiogenesis 2005; 8:89-99.

9. Nap AW, Dunselman GA, Griffioen AW, Mayo KH, Evers JL, Groothuis PG. Angiostatic agents prevent the development of endometriosis-like lesions in the chicken chorioallantoic membrane. Fertil Steril 2005; 83:793-5.

10. Nap AW, Griffioen AW, Dunselman GA, Bouma-Ter Steege JC, Thijssen VL, et al. Antiangiogenesis therapy for endometriosis. J Clin Endocrinol Metab 2004; 89:1089-95.

11. McLaren J. Vascular endothelial growth factor and endometriotic angiogenesis. Hum Reprod Update 2000; 6:45-55.

12. Negri L, Lattanzi R, Giannini E, Melchiorri P. Bv8/Prokineticin proteins and their receptors. Life Sci 2007; 81:1103-16.

13. LeCouter J, Kowalski J, Foster J, Hass P, Zhang Z, llard-Telm L, et al. Identification of an angiogenic mitogen selective for endocrine gland endothelium. Nature 2001; 412: 877-84. 
14. LeCouter J, Ferrara N. EG-VEGF and the concept of tissue-specific angiogenic growth factors. Semin Cell Dev Biol 2002; 13:3-8.

15. Zhang L, Yang N, Conejo-Garcia JR, Katsaros D, Mohamed-Hadley A, Fracchioli S, et al. Expression of endocrine gland-derived vascular endothelial growth factor in ovarian carcinoma. Clin Cancer Res 2003; 9:264-72.

16. Ferrara N, Frantz G, Lecouter J, llard-Telm L, Pham T, Draksharapu A, et al. Differential expression of the angiogenic factor genes vascular endothelial growth factor (VEGF) and endocrine gland-derived VEGF in normal and polycystic human ovaries. Am J Pathol 2003; 162: 1881-93.

17. Masuda Y, Takatsu Y, Terao Y, Kumano S, Ishibashi Y, Suenaga M, et al. Isolation and identification of EG-VEGF/prokineticins as cognate ligands for two orphan G-protein-coupled receptors. Biochem Biophys Res Commun. 2002; 293:396-402.

18. Lin DC, Bullock CM, Ehlert FJ, Chen JL, Tian H, Zhou QY. Identification and molecular characterization of two closely related $G$ protein-coupled receptors activated by prokineticins/endocrine gland vascular endothelial growth factor. $\mathrm{J}$ Biol Chem 2002; 277:19276-80.

19. Lin R, LeCouter J, Kowalski J, Ferrara N. Characterization of endocrine gland-derived vascular endothelial growth factor signaling in adrenal cortex capillary endothelial cells. J Biol Chem 2002; 277:8724-9.

20. Ngan ES, Sit FY, Lee K, Miao X, Yuan Z, Wang W, et al. Implications of endocrine gland-derived vascular endothelial growth factor/prokineticin-1 signaling in human neuroblastoma progression. Clin Cancer Res 2007; 13: 868-75.

21. Lee YL, Chan YL, Chow WN, Ng EH, Lee KF, Yeung WS, et al. Endocrine gland-derived vascular endothelial growth factor stimulates proliferation and tube formation in human uterine microvascular endothelial cell through the mitogen-activated protein kinase but not through the Akt pathway. Fertil Steril. 2008 Jun 18. [Epub ahead of print]

22. LeCouter J, Lin R, Tejada M, Frantz G, Peale F, Hillan KJ, et al. The endocrine-gland-derived VEGF homologue Bv8 promotes angiogenesis in the testis: Localization of Bv8 receptors to endothelial cells. Proc Natl Acad Sci USA $2003 ; 100: 2685-90$.

23. Pasquali D, Rossi V, Staibano S, De RG, Chieffi P, Prezioso D, et al. The endocrine-gland-derived vascular endothelial growth factor 
F \& S 5688 revision

(EG-VEGF)/prokineticin 1 and 2 and receptor expression in human prostate: Up-regulation of EG-VEGF/prokineticin 1 with malignancy. Endocrinology 2006; 147: 4245-51.

24. Fraser HM, Bell J, Wilson H, Taylor PD, Morgan K, Anderson RA, et al. Localization and quantification of cyclic changes in the expression of endocrine gland vascular endothelial growth factor in the human corpus luteum. J Clin Endocrinol Metab 2005; 90:427-34.

25. Hoffmann P, Feige JJ, Alfaidy N. Expression and oxygen regulation of endocrine gland-derived vascular endothelial growth factor/prokineticin-1 and its receptors in human placenta during early pregnancy. Endocrinology 2006; 147:1675-84.

26. Maldonado-Perez D, Evans J, Denison F, Millar RP, Jabbour HN. Potential roles of the prokineticins in reproduction. Trends Endocrinol Metab 2007; 18:66-72.

27. Samson M, Peale FV Jr, Frantz G, Rioux-Leclercq N, Rajpert-De Meyts E, Ferrara N. Human endocrine gland-derived vascular endothelial growth factor: expression early in development and in Leydig cell tumors suggests roles in normal and pathological testis angiogenesis. J Clin Endocrinol Metab 2004; 89:4078-88.

28. Sharkey AM, Day K, McPherson A, Malik S, Licence D, Smith SK, et al. Vascular endothelial growth factor expression in human endometrium is regulated by hypoxia. J Clin Endocrinol Metab 2000; 85:402-9.

29. Becker CM, Rohwer N, Funakoshi T, Cramer T, Bernhardt W, Birsner A, et al. 2-methoxyestradiol inhibits hypoxia-inducible factor-1\{alpha\} and suppresses growth of lesions in a mouse model of endometriosis. Am J Pathol 2008; 172:534-44.

30. Ngan ES, Lee KY, Yeung WS, Ngan HY, Ng EH, Ho PC. Endocrine gland-derived vascular endothelial growth factor is expressed in human peri-implantation endometrium, but not in endometrial carcinoma. Endocrinology 2006; 147: 88-95.

31. Battersby S, Critchley HO, Morgan K, Millar RP, Jabbour HN. Expression and regulation of the prokineticins (endocrine gland-derived vascular endothelial growth factor and $\mathrm{Bv} 8$ ) and their receptors in the human endometrium across the menstrual cycle. J Clin Endocrinol Metab 2004; 83: 2463-9.

32. Noyes RW, Hertig AT, Rock J. Dating the endometrial biopsy. Am J Obstet Gynecol 1975; 122:262-3. 
33. Lee KF, Xu JS, Lee YL, Yeung WS. Demilune cell and parotid protein from murine oviductal epithelium stimulates preimplantation embryo development. Endocrinology 2006; 147:79-87.

34. Livak KJ, Schmittgen TD. Analysis of relative gene expression data using real-time quantitative PCR and the 2(-Delta Delta C(T)) Method. Methods 2001; 25:402-8.

35. Budwit-Novotny DA, McCarty KS, Cox EB, Soper JT, Mutch DG, Creasman WT, et al. Immunohistochemical analysis of estrogen receptor in endometrial carcinoma using a monoclonal antibody. Cancer Res 1986; 46:5419-25.

36. Chen J, Kuei C, Sutton S, Wilson S, Yu J, Kamme F, et al. Identification and Pharmacological Characterization of Prokineticin $2 \beta$ as a Selective Ligand for Prokineticin Receptor 1. Mol Pharmacol 2005; 67:2070-6.

37. Soga T, Matsumoto S, Oda T, Saito T, Hiyama H, Takasaki J, et al. Molecular cloning and characterization of prokineticin receptors. Biochim Biophys Acta 2002; 1579: 173-9.

38. Matsumoto S, Yamazaki C, Masumoto KH, Nagano M, Naito M, Soga T, et al. Abnormal development of the olfactory bulb and reproductive system in mice lacking prokineticin receptor PKR2. Proc Natl Acad Sci USA 2006; 103:4140-5.

39. Ng KL, Li JD, Cheng MY, Leslie FM, Lee AG, Zhou QY. Dependence of olfactory bulb neurogenesis on prokineticin 2 signaling. Science 2005; 308:1923-7.

40. Park JE, Keller GA, Ferrara N. The vascular endothelial growth factor (VEGF) isoforms: differential deposition into the subepithelial extracellular matrix and bioactivity of extracellular matrix-bound VEGF. Mol Biol Cell 1993; 4:1317-26.

41. Houck KA, Leung DW, Rowland AM, Winer J, Ferrara N. Dual regulation of vascular endothelial growth factor bioavailability by genetic and proteolytic mechanisms. J Biol Chem 1992; 267:26031-7.

42. Chakraborty I, Das SK, Dey SK. Differential expression of vascular endothelial growth factor and its receptor mRNAs in the mouse uterus around the time of implantation. J Endocrinol 1995; 147:339-52.

43. Gargett CE, Lederman FL, Lau TM, Taylor NH, Rogers PA. Lack of correlation between vascular endothelial growth factor production and endothelial cell proliferation in the human endometrium. Hum Reprod 1999; 14:2080-8. 
F \& S 5688 revision

44. Hornung D, Lebovic DI, Shifren JL, Vigne JL, Taylor RN. Vectorial secretion of vascular endothelial growth factor by polarized human endometrial epithelial cells. Fertil Steril 1998; 69: 909-15.

45. Donnez J, Smoes P, Gillerot S, et al. Vascular endothelial growth factor (VEGF) in endometriosis. Hum Reprod 1998; 13:1686-90.

46. Tan XJ, Lang JH, Liu DY et al. Expression of vascular endothelial growth factor and thrombospondin-1 mRNA in patients with endometriosis. Fertil Steril 2002; 78:148-53.

47. Machado DE, Abrao MS, Berardo PT, Takiya CM, Nasciutti LE. Vascular density and distribution of vascular endothelial growth factor (VEGF) and its receptor VEGFR-2 (Flk-1) are significantly higher in patients with deeply infiltrating endometriosis affecting the rectum. Fertil Steril 2008; 90:148-55.

48. Garrido N, Albert C, Krüssel JS, O'Connor JE, Remohí J, Simón C, et al. Expression, production, and secretion of vascular endothelial growth factor and interleukin- 6 by granulosa cells is comparable in women with and without endometriosis. Fertil Steril 2001; 76:568-75. 


\section{Figure Legends}

Figure 1

Real-time PCR analysis of EG-VEGF, PKR1 and PKR2 mRNA expression levels between normal and eutopic endometrium. Eutopic endometrial samples from normal women $(\mathrm{NE})$ in proliferative (Proli, $\mathrm{n}=14$ ) and secretory phase $(\mathrm{Sec}, \mathrm{n}=19)$; and from women with endometriosis (DE) in proliferative $(n=9)$ and secretory phase $(n=6)$ were studied. The relative expression of the (A) EG-VEGF, (B) PKR1 and (C) PKR2 mRNA expressions were normalized to $18 \mathrm{~S}$ expression and calculated by the equation: $2^{-\Delta \Delta \mathrm{Ct}}$ using the proliferative phase normal endometrium (NE) as calibrator. A difference of $\mathrm{Ct}$ values $(\Delta \mathrm{Ct})$ was obtained by subtracting the $\mathrm{Ct}$ value of $18 \mathrm{~S}$ from $\mathrm{Ct}$ value of the genes of interest. The relative gene expression values were calculated by the $2^{-\Delta \Delta C t}$ method (see materials and methods). Data were presented as median with $10^{\text {th }}, 25^{\text {th }}, 75^{\text {th }}$ and $90^{\text {th }}$ percentiles and outliers $(\bullet)$. Statistical analysis was performed by Kruskal-Wallis test and p-values were shown. A p-value less than 0.05 was considered significant different from different samples.

Figure 2

Real-time PCR analysis of EG-VEGF and VEGF mRNA expression levels in paired LCM isolated eutopic and ectopic endometriotic samples. (A) Three LCM sections from ectopic or eutopic samples were used for RNA extraction. (B) The relative expressions of EG-VEGF and VEGF transcripts were normalized to $18 \mathrm{~S}$ and calculated by the equation: $2^{-\Delta \Delta \mathrm{Ct}}$ using the ectopic endometrium as calibrator. A p-value less than 0.05 was considered significant different from different samples. NS: Not significant. 
Figure 3

Immunohistochemical staining of EG-VEGF in eutopic and ectopic endometrium.

Frozen eutopic (A and C) and ectopic (B) endometrial, and archive testis (D) samples were stained with EG-VEGF (A, B and D) antibody. Specific brown signal was found in the glandular (GE) and luminal epithelium (LE) of eutopic endometrium (A), and in the stromal cells (SC) of the ectopic endometrium (B) of the same patient and no signal was found when the primary antibody was omitted (C). Leydig cells (Le) of frozen human testicular sample were positively stained with EG-VEGF antibody, but not in spermatozoa (Sp) in the seminiferous tubule (D). The expression of EG-VEGF protein in twelve pairs of endometriotic samples was determined by H-scoring. Significant difference was found in the stromal cells (E), but not glandular epithelium (F) of ectopic and eutopic endometrium $(\mathrm{p}=0.011)$. 
Table 1 Messenger RNA expression of EG-VEGF, PKR1 and PKR2 in eutopic endometria of normal women and diseased women with endometriosis. The transcript expression levels were expressed as median of $\mathrm{Ct}$ values (ranges). ${ }^{*} \mathrm{P}<0.05$ when compared with the proliferative phase.

\begin{tabular}{|c|c|c|c|c|}
\hline \multirow{2}{*}{ mRNA } & \multicolumn{2}{|c|}{ Normal women } & \multicolumn{2}{c|}{ Women with endometriosis } \\
\cline { 2 - 5 } & Proliferative & Secretory & Proliferative & Secretory \\
\hline \multirow{2}{*}{ EG-VEGF } & $0.03^{\mathrm{a}}$ & $1.50^{\mathrm{a}}$ & 0.04 & 0.28 \\
& $\left(5.2 \times 10^{-6}-1.0\right)$ & $(0.0-27.9)$ & $\left(2.9 \times 10^{-4}-0.6\right)$ & $\left(2.0 \times 10^{-4}-5.6\right)$ \\
\hline \multirow{2}{*}{ PKR1 } & $3.92^{\mathrm{b}}$ & $0.64^{\mathrm{b}}$ & 1.89 & 0.43 \\
\hline \multirow{2}{*}{ PKR2 } & $(0.0-23.4)$ & $(0.0-6.7)$ & $(0.1-5.5)$ & $(0.0-2.1)$ \\
\hline & $(0.0-6.6)$ & $(0.0-1.0)$ & $(0.0-10.7)$ & $(0.0-1.2)$ \\
\hline
\end{tabular}

$a-a, b-b, c-c, d-d$ are statistically difference $(p<0.05)$ between groups 
Figure 1

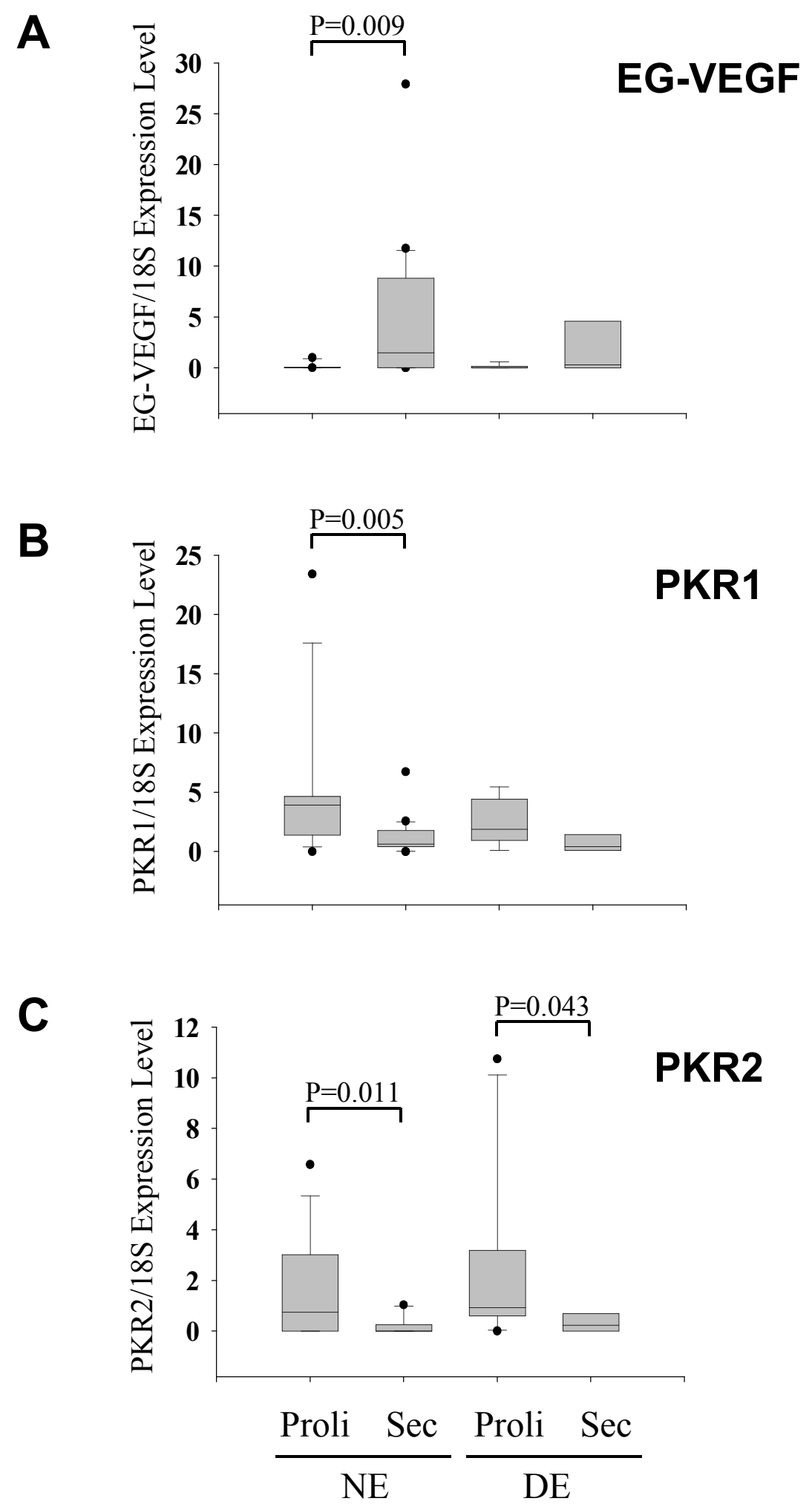


Figure 2

A
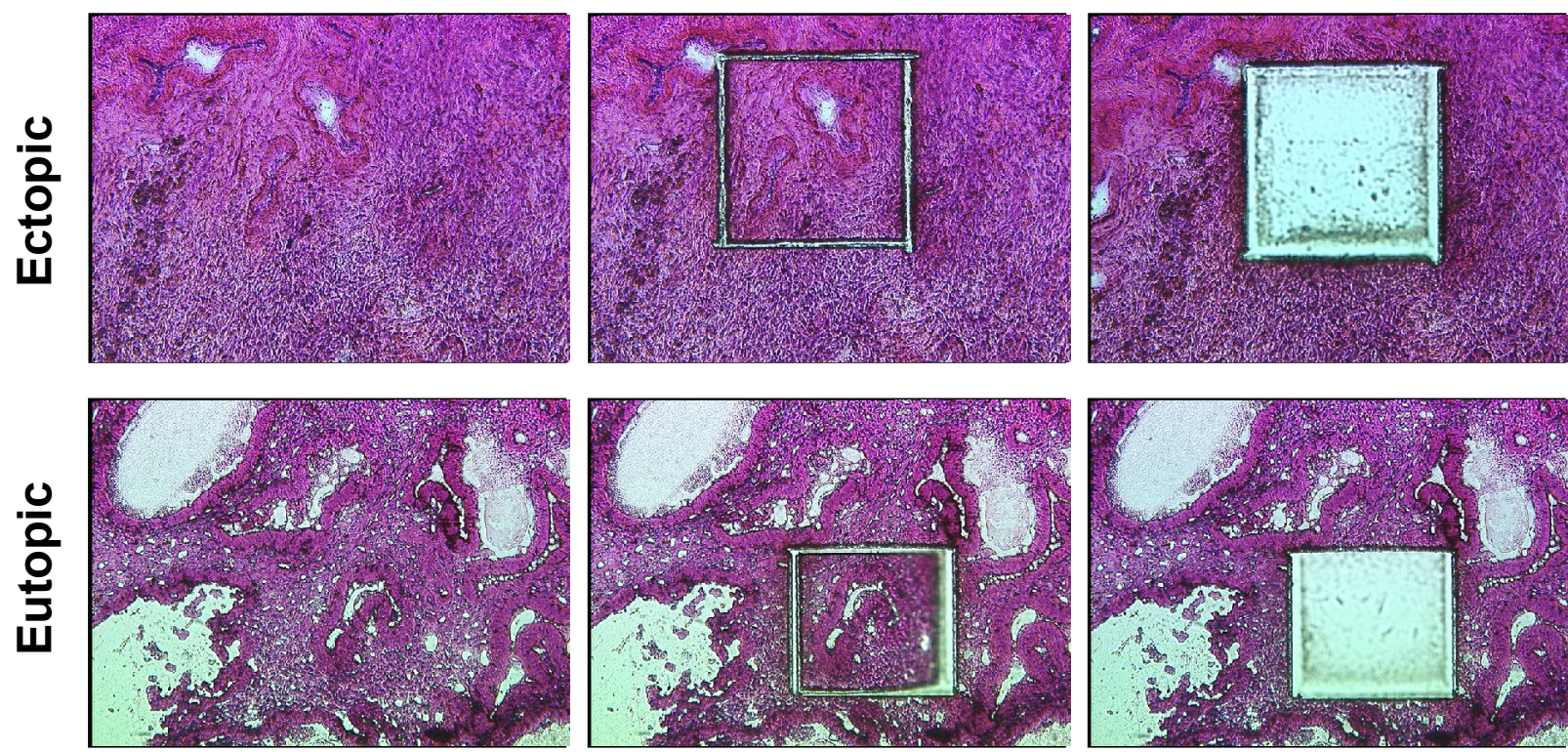

B
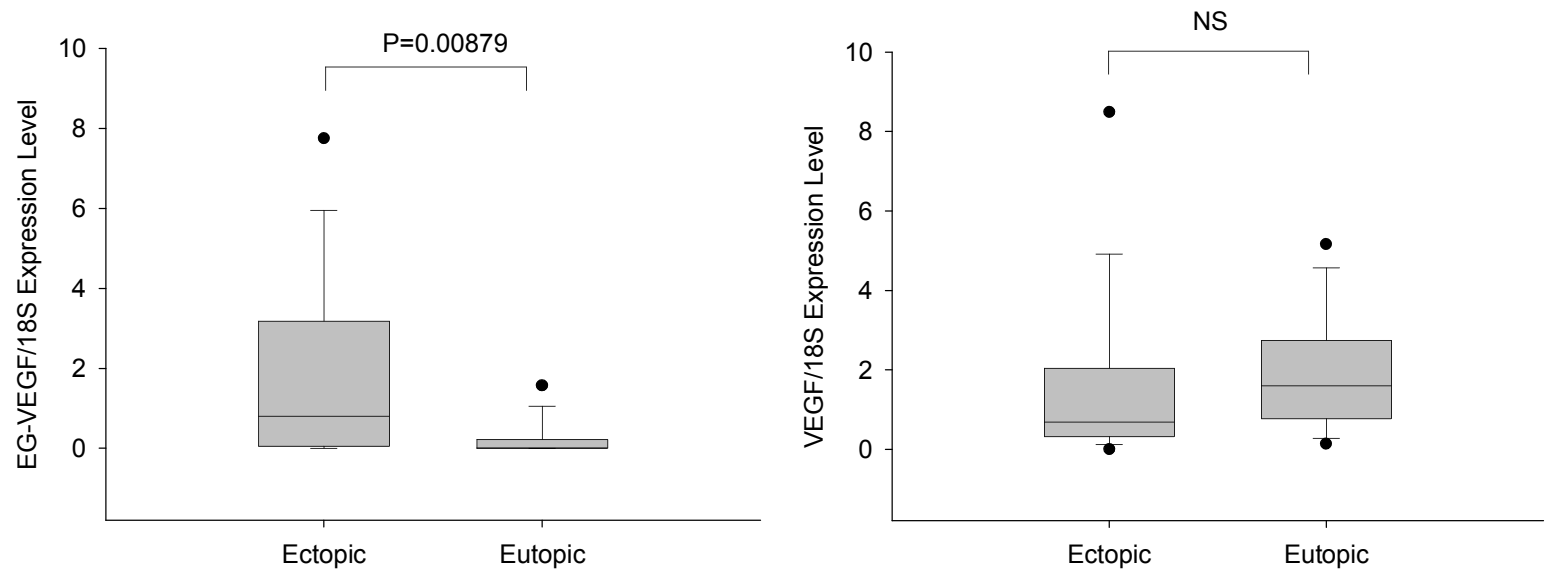


\section{Figure 3}
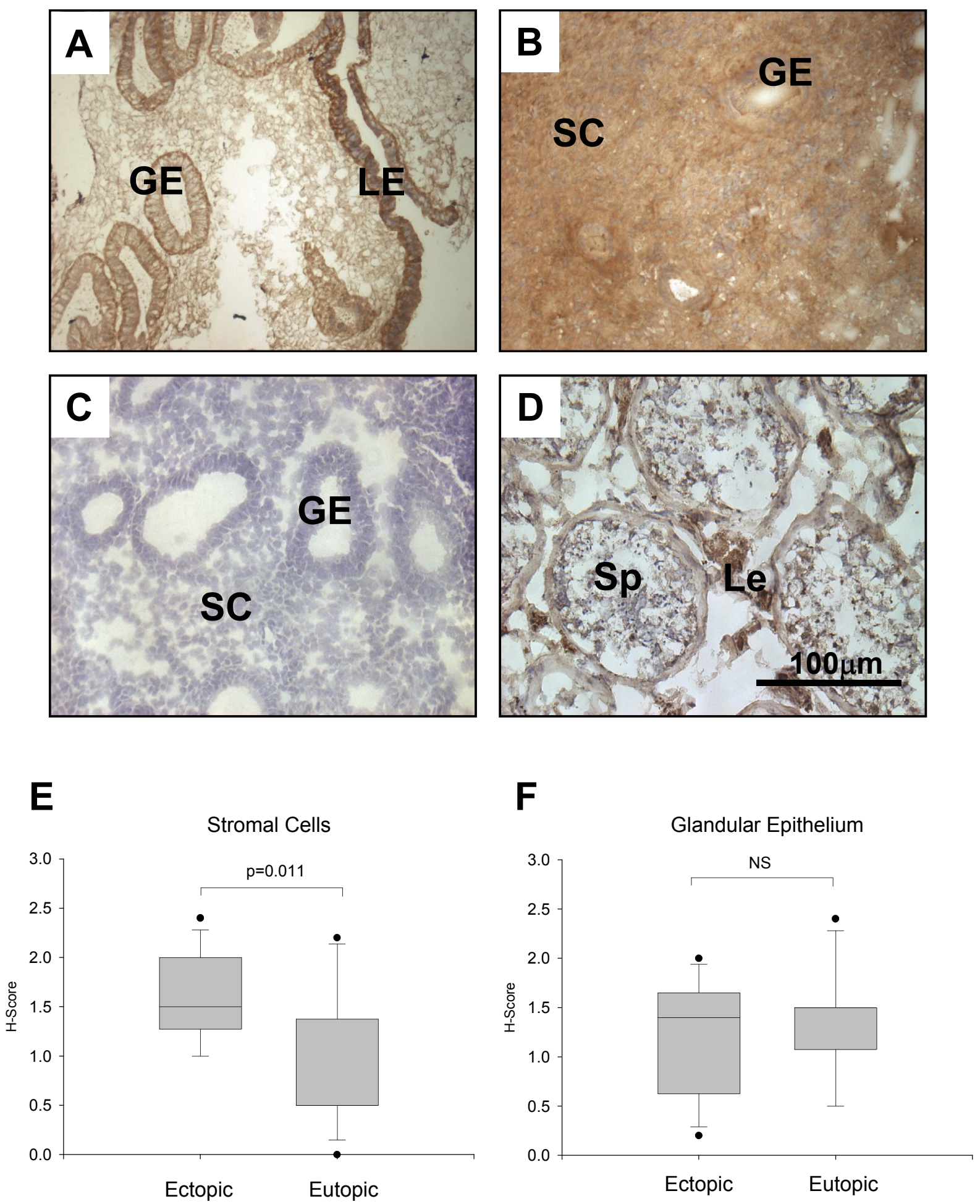